\title{
FIREFIGHTERS CARDIORESPIRATORY FITNESS PARAMETERS AFTER 24 WEEKS OF FUNCTIONAL TRAINING WITH AND WITHOUT PERSONAL PROTECTIVE EQUIPMENT
}

\author{
NUNO LAJOSO-SILVA, PEDRO BEZERRA², BRUNO SILVA², JOSÉ MARIA CANCELA CARRAL ${ }^{1}$ \\ IUniversity of Vigo, Faculty of Educational Sciences E Sports Sciences, Pontevedra, Spain \\ 2Instituto Politécnico de Viana do Castelo, Escola Superior Desporto e Lazer, Viana do Castelo, Portugal
}

\author{
Mailing address: Bruno Silva, Instituto Politécnico de Viana do Castelo, 4900-347 Viana do Castelo, Portugal, \\ e-mail: silvabruno@esdl.ipvc.pt
}

\begin{abstract}
Introduction. Firefighters' (FFs) cardiorespiratory fitness is considered an important capacity for workability. To successfully complete safety standards and rescue protocols, FFs are required to accomplish minimum values of relative $\mathrm{VO}_{2 \max }$. $\mathrm{Physical}$ fitness programs for FFs must take into consideration physiological demands, being essential not only for professional tasks but also as a guarantee of their personal safety. This research aimed to investigate the influence of specific functional training (FT) with and without personal protective equipment (PPE) and self-contained breathing apparatus (SCBA) on the FFs' cardiorespiratory fitness. Material and methods. Sixty FFs were randomly allocated in three groups (EG1 training with PPE+SCBA; EG2 training with regular fitness equipment and the control group) and enrolled for a 24-week (two sessions/week) FT intervention program. FFs were assessed in anthropometric and 12-minute Cooper test, pre and post-intervention. Results. Both training groups demonstrated significant improvements from baseline to post intervention EG1 VO $\mathrm{Vmax}_{2}\left(39.8 \pm 6.5 \mathrm{ml} \mathrm{kg}^{-1} \cdot \mathrm{min}^{-1} \mathrm{and}_{41.2}\right.$ $\pm 5.6 \mathrm{ml} \cdot \mathrm{kg}^{-1} \cdot \mathrm{min}^{-1}, \mathrm{p}<0.001,+3.5 \%$; EG2 VO $\mathrm{VO}_{\max } 41.5 \pm 8.3 \mathrm{ml} \cdot \mathrm{kg}^{-1} \cdot \mathrm{min}^{-1}$ and $\left.42.5 \pm 7.5 \mathrm{ml} \cdot \mathrm{kg}^{-1} \cdot \mathrm{min}^{-1}, \mathrm{p}<0.05,+2.4 \%\right)$. Conclusions. The proposed FT intervention, considering the provided equipment in all fire departments, and even without running tasks, seems to be adequate for developing $\mathrm{FFs}^{\prime} \mathrm{VO}_{2 \max }$. Regular FT with PPE+SCAB must be encouraged to improve adequate VO2max and fitness levels related to firefighting specific tasks.
\end{abstract}

Key words: physical training, physical fitness, self-contained breathing apparatus

\section{Introduction}

To carry out their professional demands, firefighters (FFs) must have excellent physical fitness (PF) levels, as their work capacity includes performing tasks such as pulling a hose, carrying a ladder or rescuing victims [1]. Inadequate fitness levels may reduce FFs' occupational performance [2]. Physiological demands are reflected in metabolic, circulatory, thermoregulatory responses, and hydration status, while psychological tension may be partially reflected in heart rate and endocrine measures [3]. An extra level of physical fitness may be needed when psychic stress and exposure to heat represent an additional burden on the cardiovascular system, leading to reduced efficiency, increased effort and early appearance of fatigue even in younger and well-prepared FFs [4]. In fact, there is an increased risk of cardiovascular disease (CVD), since between 45 and $50 \%$ of FFs' deaths occur during strenuous emergency duties compared to those of a non-emergency nature [5].

Firefighters' cardiorespiratory fitness (CF) is thus considered an important capacity for workability [6] with an estimated $27 \%$ to $86 \%$ of total energy expenditure during firefighting tasks being carried out through this route [7]. Among the different physiological parameters, maximum oxygen consumption $\left(\mathrm{VO}_{2 \max }\right)$ is the variable most frequently considered [8].

To successfully complete safety standards and rescue protocols, FFs are required to accomplish minimum values of relative $\mathrm{VO}_{2 \max }\left(>33 \mathrm{ml} \cdot \mathrm{kg}^{-1} \cdot \mathrm{min}^{-1}\right.$; preferably $\left.>45 \mathrm{ml} \cdot \mathrm{kg}^{-1} \mathrm{~min}^{-1}\right)[7,9]$.
These values result in oxygen consumption levels between $63 \%$ and $97 \%$ of $\mathrm{VO}_{2 \max }[10]$ and were observed during the conduct of simulated firefighting tasks.

In general, $90 \%$ of the most common activities require average $\mathrm{VO}_{2 \max }$ between 23.4 and $31 \mathrm{ml} \cdot \mathrm{kg}^{-1} \cdot \mathrm{min}^{-1}$, and 41.1 and 49.3 $\mathrm{ml} . \mathrm{kg}^{-1} . \mathrm{min}^{-1}$ for more demanding tasks [8]. O'Connell et al., [11] reported that climbing stairs in a simulated fire situation for 5 minutes with protective and respiratory equipment requires average $\mathrm{VO}_{2 \max }$ of $39.0 \mathrm{ml} \cdot \mathrm{kg}^{-1} \cdot \mathrm{min}^{-1}$, while Gledhill \& Jamnik [8] described values from 23.4 to $25.7 \mathrm{ml} \cdot \mathrm{kg}^{-1} \cdot \mathrm{min}^{-1}$ for lifting and moving hoses, $30.9 \mathrm{ml} . \mathrm{kg}^{-1} \cdot \mathrm{min}^{-1}$ in the control of a flexible tube and 36.6 to $44.0 \mathrm{ml} \cdot \mathrm{kg}^{-1} \cdot \mathrm{min}^{-1}$ for upstairs equipment carrying.

However, in several professional contexts, FFs must use personal protective equipment (PPE) and self-contained breathing apparatuses (SCBAs). Such equipment increases muscle tension, affects users' mobility, decreases range of motion, thus leading to imbalance in gait mechanics and movement patterns and an increase in their task completion time [12]. PPE and SCBAs add loads from 11 and $\geq 25 \mathrm{~kg}$, significantly influencing metabolic, thermal and fatigue efficiency [7].

Carrying heavy equipment and wearing restrictive clothing in extreme heat while performing high-intensity firefighting work causes significant physiological stress that, when combined with deficient PF, can lead to CVD events in the course of action [13]. For these reasons, it is important to emphasize that the maximum performance of FFs, determined from typical 
$\mathrm{VO}_{2 \max }$ tests without the use of PPE+SCBAs, may overestimate the real performance capacity in a real situation [14].

Physical fitness programs for FFs must take into consideration physiological demands, being essential not only for professional tasks but also as a guarantee of their personal safety (7). Conventional periodization models improve the performance of FFs in terms of specific physical skills. However, several minutes of rest must be given between sets and repetitions, which does not optimize the stress in the anaerobic and aerobic energy systems, as is the case during real events [15]. In contrast, shortterm functional training (FT), which is characterized by short rest periods and relatively high intensity, can place energy production systems in a state of physiological stress that is closer to those that are experienced during real firefighting tasks [16]. FT may be a growing field in intervention to investigate as it attempts to adapt or develop exercises close to a specific task, involving multi-planar, coordinated, and multi-articular movements. As such, little is known about strategies that might make fitness training more effective [16].

Consequently, it is essential to use training methods that effectively address the multilateral development of such component.

Considering the importance of tailoring effective and time-efficient FT, this study aimed to assess the relevance of an innovative FFs specific FT intervention without a running-related task in improving FFs' cardiorespiratory fitness. Furthermore, this study also aimed to examine how the use of PPE+SCBA or its lack influences FFs' cardiorespiratory fitness improvements.

\section{Material and methods}

This FT intervention program was carried out for 24 weeks, including a pre (week -1) and post (week 25) assessment. During week -1, FFs were assessed based on anthropometric measures and cardiorespiratory fitness. The subjects wore training clothes and shoes, performing anthropometric tests before the cardiorespiratory fitness test, and were asked to 1) avoid consuming food two hours before the tests, 2) abstain from drinking alcohol and taking stimulants, and 3) abstain from exercising intensely during the 24 hours before the tests. All anthropometric assessment sessions took place at FFs' headquarters facilities. The Cooper test was performed on regular athletics tracks (400 meters per lap). Before the study, all the participants were informed of the objectives, procedures, and protocols, and they all voluntarily signed an informed consent form. The study was carried out following the Helsinki Declaration recommendations for studies in humans and was authorized by the local ethics committee, which gave their ethical clearance (CTC-ESDL-CE002-2019).

\section{Participants}

A convenience sample of 60 male Portuguese FFs $(30.8 \pm$ 6.5 years; $78.5 \pm 13.5 \mathrm{~kg} ; 172.6 \pm 6.4 \mathrm{~cm})$ was randomly divided into three groups: training group one $(30.9 \pm 8.0$ years; $79.6 \pm$ $11.6 \mathrm{~kg} ; 172.1 \pm 6.3 \mathrm{~cm}$ ) - EGl (training with PPE+SCBA), training group two $(30.3 \pm 6.4$ years; $76.4 \pm 5.2 \mathrm{~kg} ; 172.8 \pm 5.2 \mathrm{~cm})-\mathrm{EG} 2$ (training with regular equipment) and control group (31.9 \pm 4.6 years; $79.7 \pm 16.0 \mathrm{~kg}$; $173.2 \pm 8.2 \mathrm{~cm}$ ). Group EGl exercised with PPE+SCBA during each session without breathing through (Fig. 1), whereas group EG2 performed the same exercises but without PPE+SCBA.

The inclusion criteria were (i) belonging to the Permanent Intervention Team (PIT), (ii) being over 18 years of age, (iii)

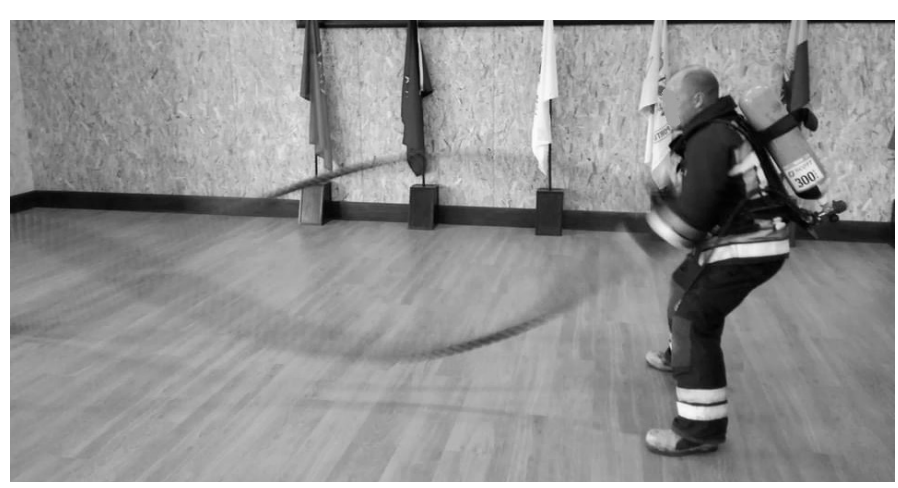

Figure 1. Example of firefighter training with personal protective equipment and self-contained breathing apparatus without breathing through

showing interest in participating in the study, and (iv) passing the annual medical exam.

\section{Anthropometric tests}

According to the protocol of the International Society for the Advancement of Kinanthropometry [17], each FF was assessed in terms of height to the nearest $0.1 \mathrm{~cm}$ with a portable stadiometer (SECA 217, Hamburg, Germany) and weight (SECA 760 , Hamburg, Germany) to the nearest $0.5 \mathrm{~kg}$ with a scale.

\section{Cardiorespiratory Fitness}

Cardiorespiratory fitness was assessed with the Cooper test. This easy and reliable test was used because of its high correlation with maximum oxygen consumption $(r=0.90)$, [18] economic and safety reasons since it is performed annually as a requirement to be part of FFs' PITs [19].

A 400-meter official athletics track was used to assess the distance covered, and a Geomaute, Onstart 300 stopwatch was used to control the test time. Two trained and experienced researchers supervised the test and assessed the meters covered.

The FFs were allocated in groups of 8 elements, carrying a distinctive color mark. Ten minutes before starting the test, a standard warm-up was carried out by the researchers. The warm-up comprised 6 minutes of running at a self-selected pace followed by two sets of ten repetitions of walking lunges, front leg swings, side leg swings, iron cross and "groiners".

The test began under the command voice "Attention! Start!". At that moment, the chronometer was started and the FFs began running. During the test, the FFs were informed individually about the remaining time after each lap, and the countdown began in the last 10 seconds. The end of the 12 minutes was announced with the sound of a whistle. The subjects were encouraged to cover the longest distance possible; they were allowed to walk if necessary but they were asked to avoid this behaviour. After the end of the test, the subject left a mark on the spot and continued walking for 3 to 5 minutes to facilitate recovery. In the end, the total number of meters covered was recorded on an individual form for further analysis. For assessing $\mathrm{VO}_{2 \max }\left(\mathrm{ml} \cdot \mathrm{kg}^{-1} \cdot \mathrm{min}^{-1}\right)$, the equation of Heyward \& Gibson [18] was used, based on the maximum distance covered in the 12 minutes $\left(\mathrm{VO}_{2 \max }\left(\mathrm{ml} . \mathrm{kg}^{-1} \cdot \mathrm{min}^{-1}\right)=0.0268 \times\right.$ (distance covered in meters) - 11.3).

\section{Intervention program}

The FT intervention program was carried out for a period of 24 weeks, two sessions per week, divided into 4 phases. Phase 1 (mesocycle adaptation) lasted 4 weeks; phase 2 (mesocycle 
Gain 1) took 8 weeks; phase 3 (mesocycle Gain 2) took 4 weeks; phase 4 (mesocycle improvement) lasted 8 weeks (Tab. 1).

The training program included 12 functional fitness exercises for FFs. The exercise program included a general warmup followed by the workout which, depending on the mesocycle, was organized as stations or in circuit. In each exercise, station/ circuit-specific information was provided to identify the exercises to be performed and the order in which they should be performed. All exercises were demonstrated under specific progressive challenges and by a proficient subject, to ensure their correct execution. Weekly meetings provided education on proper movements and progressions used in the FT program.

The training load was increased according to training principles (i.e., by increasing the load, frequency, volume, complexi-

Table 1. Example of the Functional Training intervention macrocycle plan

\begin{tabular}{|c|c|c|}
\hline \multicolumn{3}{|c|}{ PHASE I - Mesocycle Adaptation (4 weeks/2x week) } \\
\hline $\begin{array}{c}\text { Objective } \\
\text { low/moderate } \\
\text { General fatigue } \\
\text { Intensity } \\
50-65 \% \text { da MaxHR }\end{array}$ & $\begin{array}{c}\text { Station training } \\
1 \text { set per exercise x2 } \\
\text { Exercises sequence } \\
\text { S1 (1-2-3, 1-2-3); } \\
\text { S2 (4-5-6, 4-5-6); } \\
\text { S3 (7-8-9, 7-8-9); } \\
\text { S4 (10-11-12, 10-11-12) }\end{array}$ & $\begin{array}{l}\text { Workout time } \\
\text { 30" Exercise } \\
\text { 20" Rest } \\
\text { Total Timing } \\
\text { 24:30 }\end{array}$ \\
\hline \multicolumn{3}{|c|}{ PHASE II - Mesocycle Gain 1 (8 weeks/2x week) } \\
\hline $\begin{array}{c}\text { Goal } \\
\text { moderate/intense } \\
\text { Local fatigue } \\
\text { Intensity } \\
65-75 \% \text { da MaxHR }\end{array}$ & $\begin{array}{c}\text { Station training } \\
2 \text { sets per exercise x2 } \\
\text { Exercises sequence } \\
\text { S1 (1-1-2-2-3-3); } \\
\text { S2 (4-4-5-5-6-6); } \\
\text { S3 (7-7-8-8-9-9); } \\
\text { S4 (10-10-11-11-12-12) }\end{array}$ & $\begin{array}{l}\text { Workout } \\
\text { 45" Exercise } \\
\text { 20" Rest } \\
\text { Total Timing } \\
\text { 29:00 }\end{array}$ \\
\hline \multicolumn{3}{|c|}{ PHASE III - Mesocycle Gain 2 (4 weeks/2x week) } \\
\hline $\begin{array}{c}\text { Goal } \\
\text { moderate/intense } \\
\text { General fatigue } \\
\text { Intensity } \\
65-75 \% \text { da MaxHR }\end{array}$ & $\begin{array}{c}\text { Station training } \\
3 \text { sets per exercise x3 } \\
\text { Exercises sequence } \\
\text { S1 (1-2-3, 1-2-3, 1-2-3); } \\
\text { S2 (4-5-6, 4-5-6, 4-5-6); } \\
\text { S3 (7-8-9, 7-8-9, 7-8-9); } \\
\text { S4 (10-11-12, 10-11-12) }\end{array}$ & $\begin{array}{l}\text { Workout } \\
\text { 60" Exercise } \\
\text { 20" Rest } \\
\text { Total Timing } \\
51: 00\end{array}$ \\
\hline \multicolumn{3}{|c|}{ PHASE IV - Mesocycle Improvement (8 weeks/2x week) } \\
\hline $\begin{array}{c}\text { Goal } \\
\text { very intense } \\
\text { General fatigue } \\
\text { Intensity } \\
\text { 80-90\% da MaxHR }\end{array}$ & $\begin{array}{c}\text { Circuit training } \\
\text { 1 set per exercise } x 2 \mathrm{C} \\
\text { Exercises sequence } \\
\text { C1 }(1-2-3-4 \ldots 10,11,12) ; \\
\text { C2 }(1-2-3-4 \ldots 10,11,12)\end{array}$ & $\begin{array}{c}\text { Workout } \\
60 " \text { Exercise } \\
15 " \text { Rest } \\
\text { Total Timing } \\
\text { 31:30 }\end{array}$ \\
\hline
\end{tabular}

S - Station; C - Circuit; MaxHR - Maximum heart rate; " - seconds.

Table 2. Cardiorespiratory fitness of the firefighters, pre and post intervention

\begin{tabular}{|c|c|c|c|c|c|c|c|c|c|c|c|c|}
\hline Cooper test & $\begin{array}{c}\text { EG1 } \\
(n=22) \\
\text { Mean } \pm \text { SD }\end{array}$ & $p$ value & $\%$ dif & ES & $\begin{array}{c}\text { EG2 } \\
(n=21) \\
\text { Mean } \pm \text { SD }\end{array}$ & $p$ value & $\%$ dif & ES & $\begin{array}{c}\text { CG } \\
(n=17) \\
\text { Mean } \pm \text { SD }\end{array}$ & $p$ value & $\%$ dif & ES \\
\hline Estimated $\mathrm{VO}_{2 \max }$ at baseline & $39.8 \pm 6.5$ & \multirow[t]{2}{*}{0.000} & \multirow[t]{2}{*}{+3.5} & \multirow[t]{2}{*}{0.230} & $41.5 \pm 8.3$ & \multirow[t]{2}{*}{0.031} & \multirow[t]{2}{*}{+2.4} & \multirow[t]{2}{*}{0.126} & $37.0 \pm 4.9$ & \multirow[t]{2}{*}{0.651} & \multirow[t]{2}{*}{-0.5} & \multirow[t]{2}{*}{0.041} \\
\hline Estimated $\mathrm{VO}_{2 \max }$ post intervention & $41.2 \pm 5.6$ & & & & $42.5 \pm 7.5$ & & & & $36.8 \pm 4.8$ & & & \\
\hline Meters covered at baseline & $2288.2 \pm 247.0^{*}$ & \multirow[t]{2}{*}{0.000} & \multirow[t]{2}{*}{+2.5} & \multirow[t]{2}{*}{0.232} & $2365.4 \pm 372.0 * \#$ & \multirow{2}{*}{0.040} & \multirow[t]{2}{*}{+1.7} & \multirow[t]{2}{*}{0.113} & $2159.1 \pm 218.5$ & \multirow[t]{2}{*}{0.873} & \multirow[t]{2}{*}{-0.1} & \multirow[t]{2}{*}{0.009} \\
\hline Meters covered post intervention & $2346.2 \pm 252.4^{*}$ & & & & $2405.7 \pm 338.3^{*} \#$ & & & & $2156.9 \pm 215.8$ & & & \\
\hline
\end{tabular}

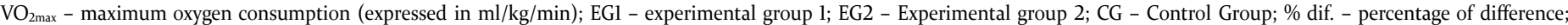
ES - Effect size; * - significant differences between baseline and post intervention; \# - + significant differences between CG and EG2 (p < 0.05 ).
Figure 2. Functional training intervention exercise plan

\section{Statistical analyses}

Descriptive statistics were calculated to provide a profile for each measured factor. According to the variable's normal distribution, the paired and independent sample t-tests were performed. Furthermore, Bonferroni post hoc analyses were employed when appropriate to determine between-group, as well as pre, post, and pre-to-post intervention differences. Additionally, the effect sizes (ES) were assessed according to Cohen's $\mathrm{d}$ using the pooled standard deviation of the random effects, considering that $\mathrm{d}=0.2$ small effect size, 0.5 represents a 'medium' effect size and 0.8 a large effect size [21]. All statistics were performed using SPSS software (version 24 for Windows, IBM, USA) with a confidence level of $95 \%$.

\section{Results}

The descriptive data of FFs' physical fitness conditions, both before and after the FT intervention, are presented in Table 2.

Significant changes were found from baseline to post-intervention in the $\mathrm{CF}$, according to the Cooper test. Both training groups demonstrated significant improvements from baseline ty or instability). Training intensity was individually normalized HR) $\mathrm{x} \%$ intensity) + resting HR] (20), and controlled in the imlifting exercises designed to use the available equipment in a fire station (e.g., weight racks, benches) or on the fire ground (e.g., carrying equipment, dragging a dummy) (Fig. 2).

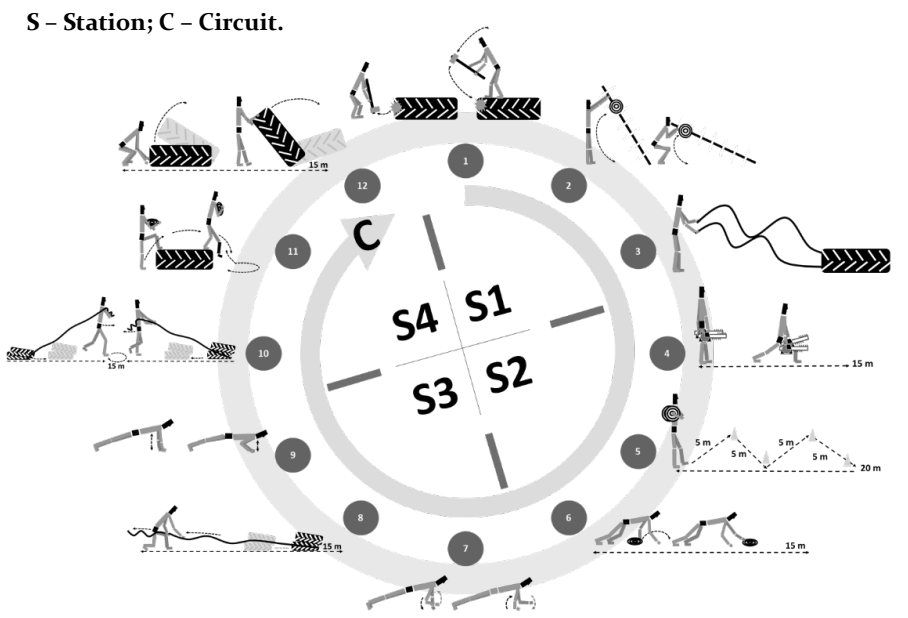


to post-intervention in meters covered (EG1 meters covered from $2288.2 \pm 247.0 \mathrm{~m}$ to $2346.2 \pm 252.4$, $\mathrm{p}<0.05,+2.5 \%$; EG2 meters covered from $2365.4 \pm 372.0 \mathrm{~m}$ to $2405.7 \pm 338.3 \mathrm{~m}$, $\mathrm{p}<0.05,+1.7 \%)$, and in estimated $\mathrm{VO}_{2 \max }\left(\mathrm{EG} \mathrm{VO}_{2 \max }\right.$ from 39.8 $\pm 6.5 \mathrm{ml} . \mathrm{kg}^{-1} \cdot \mathrm{min}^{-1}$ to $41.2 \pm 5.6, \mathrm{ml} \cdot \mathrm{kg}^{-1} \cdot \mathrm{min}^{-1}, \mathrm{p}<0.001,+3.5 \%$; EG2 $\mathrm{VO}_{2 \max }$ from $41.5 \pm 8.3 \mathrm{ml} . \mathrm{kg}^{-1} \cdot \mathrm{min}^{-1}$ to $42.5 \pm 7.5 \mathrm{ml} . \mathrm{kg}^{-1}$. $\left.\min ^{-1}, \mathrm{p}<0.05,+2.4 \%\right)$.

\section{Discussion}

The complexity and nature of FFs' duties and heavy PPE require excellent $\mathrm{CF}$. The findings of this study indicate that the implemented specific FT program was relevant in the improvement of FFs' CF independent of training modality (with or without PPE+SCBA). However, despite the similarity of the two interventions, EGl (PPE+SCBA) had the greatest increase, observed as $\%$ of difference and effect size, when compared to EG2 (no PPE+SCBA) and CG. Exercising under the conditions $\mathrm{PPE}+\mathrm{SCBA}$ might generate more beneficial outcomes in the long term because of a more accurate simulation of the actions carried out by FFs on daily interventions and promoted an extra overload during the intervention program. Our results also indicate that the Cooper test and the estimation of $\mathrm{VO}_{2 \max }$ from the total distance covered with the equation from Heyward \& Gibson [18] are useful and may provide substantial predictive validity on assessments in FFs' performance.

Several studies associate low $\mathrm{VO}_{2 \max }$ values in FFs with specific factors such as modifiable factors, task factors and equipment factors. As a task factor, we can identify the use of PPE and SCBA by decreasing aerobic capacity at a rate of $12 \%$ and $17 \%$, respectively $[22,23]$; the type of tactics chosen for the execution of tasks [24]; types of warm environments and contaminated atmospheres $[4,25]$. The equipment factors rely on technical and thermoregulation properties of textiles used in protective equipment, with an important impact on the thermal physiological responses. The $\mathrm{VO}_{2 \max }$ values (predicted) presented by our FFs are in accordance with the literature for the most common tasks of this population and physical evaluation tests. Our intervention registered significant improvements in $\mathrm{VO}_{2 \max }$ values in EGl $\left(\mathrm{VO}_{2 \max } 41.2 \pm 5.6 \mathrm{ml} \cdot \mathrm{kg}^{-1} \cdot \mathrm{min}^{-1}, \mathrm{p}<0.001\right)$, and EG2 $\left(\mathrm{VO}_{2 \max } 42.5 \pm 7.5 \mathrm{ml} . \mathrm{kg}^{-1} \cdot \mathrm{min}^{-1}, \mathrm{p}<0.05\right)$. However, there are values below $43 \mathrm{ml} . \mathrm{kg}^{-1} \cdot \mathrm{min}^{-1}$, which have been associated with an injury incidence of 2.2 times higher compared to those who demonstrate aerobic capacity greater than $48 \mathrm{ml} \cdot \mathrm{kg}^{-1} \cdot \mathrm{min}^{-1}$ [26]. Therefore, and even with notable improvements, these PIT FFs must continue to increase aerobic capacities to guarantee that FFs' tasks require less effort and thus provide a higher safety margin in daily tasks (27). Comparing the results with similar studies, which used a running test to determine $\mathrm{VO}_{2 \max }$, our findings show similar capacity scores to Italian [28], American [29], Australian (6) and Spanish [30] FFs. Lower values were found in Brazilian [31], Swedish [32], Norwegian [9], American $[26,33]$, Spanish [34], Canadian [10] and Italian [7, 35] FFs. These differences may be probably mediated by cultural background and because in Portugal PITs are a new concept relaying in the reconversion of volunteer FFs that must pass the Cooper test annually to be part of PITs [19]. This evidence may be observed in baseline results, where EGl present inferior values that EG2, but also strengthening the evidence of the benefits of the FT intervention with PPE + SCBA [36]. The scores on $\mathrm{VO}_{2 \max }$ and meters covered in EG1 and EG2 improved significantly post intervention, demonstrating the effectiveness of this FT intervention. This effect guarantees that for FFs' cardiovascular training, running may be a secondary task, as the goal was to improve
CF assessed by running tests. Another important indicator was that these achievements contribute significantly to improving our participants' operational capacity, resilience to FFs' mission, injuries and reducing CVD risk factors.

This study has some limitations. The sample size was limited to a convenience sample and did not include females, making it impossible to conduct a similar analysis. Additionally, the participants may not have been representative of all firefighters across Portugal, the habitual physical activity was not controlled, and the participants may have been in different work rotations, which may have impacted their physical state. However, this department was like most fire departments across Portugal and other countries that have no formal wellness or fitness program leading to an excellent opportunity to improve FFs' capability. Regular training with PPE+SCAB must be encouraged but under appropriate supervision and in a normally hydrated state and low ambient temperatures, so as not to induce heat illness, because thermoregulatory cooling mechanisms are rendered ineffective due to the thermal barrier produced by the PPE [37].

If heat stress is a concern, alternative methods such as increasing load carriage, with a weighted vest or just wearing the SCBA without turnout gear, may be considered. This kind of training helps FFs maintain a healthy general physical condition and develop fitness attributes that are associated with occupational performance [16].

\section{Conclusions}

A modern functional training, based on FFs' professional functions, and even without running-specific tasks, enhances FFs' cardiorespiratory fitness.

Regular functional training with $\mathrm{PPE}+\mathrm{SCAB}$ must be encouraged to improve adequate physical fitness and $\mathrm{VO}_{2 \max }$, developing a healthy general physical condition and optimum fitness levels related to firefighting-specific tasks.

The proposed functional training intervention, considering the provided equipment in all fire departments, seems to be adequate for developing $\mathrm{FFs}^{\prime} \mathrm{VO}_{2 \max }$ and running capacity.

\section{Acknowledgements}

The authors thank all firefighters and fire departments for their permission and support of this research.

\section{References}

1. Pawlak R., Clasey J.L., Palmer T., Symons T.B., Abel M.G. (2015). The effect of a novel tactical training program on physical fitness and occupational performance in firefighters. The Journal of Strength $\mathcal{E}$ Conditioning Research 29(3), 578-588. DOI: 10.1519/JSC.0000000000000663

2. Dennison K.J., Mullineaux D.R., Yates J.W., Abel M.G. (2012). The effect of fatigue and training status on firefighter performance. The Journal of Strength $\mathcal{E}$ Conditioning Research 26(4), 1101-1109. DOI: 10.1519/JSC.0b013e31822dd027

3. Barr D., Gregson W., Reilly T. (2010). The thermal ergonomics of firefighting reviewed. Applied Ergonomics 41(1), 161172. DOI: 10.1016/j.apergo.2009.07.001

4. Larsen B., Snow R., Williams-Bell M., Aisbett B. (2015). Simulated firefighting task performance and physiology under very hot conditions. Frontiers in Physiology 6, 322. DOI: 10.3389/fphys.2015.00322

5. Achmat G., Leach L., Onagbiye S.O. (2019). Prevalence of the risk factors for cardiometabolic disease among firefi- 
ghters in the Western Cape province of South Africa. The Journal of Sports Medicine and Physical Fitness 59(9), 15771583. DOI: 10.23736/S0022-4707.19.09137-0

6. Phillips M., Petersen A., Abbiss C.R., Netto K., Payne W. et al. (2011). Pack hike test finishing time for Australian firefighters: pass rates and correlates of performance. Applied Ergonomics 42(3), 411-418. DOI: 10.1016/j.apergo.2010.08.020

7. Perroni F., Tessitore A., Cortis C., Lupo C., D’artibale E. et al. (2010). Energy cost and energy sources during a simulated firefighting activity. The Journal of Strength $\mathcal{E}$ Conditioning Research 24(12), 3457-3463. DOI: 10.1519/ JSC.0b013e3181b2c7ff

8. Gledhill N., Jamnik V.K. (1992). Characterization of the physical demands of firefighting. Canadian Journal of Sport Sciences 17(3), 207-213.

9. von Heimburg E., Medbø J.I. (2013). Energy cost of the Trondheim firefighter test for experienced firefighters. International Journal of Occupational Safety and Ergonomics 19(2), 211-225. DOI: 10.1080/10803548.2013.11076980

10. Williams-Bell F.M., Villar R., Sharratt M.T., Hughson R.L. (2009). Physiological demands of the firefighter Candidate Physical Ability Test. Medicine E Science in Sports E Exercise 41(3), 653-662. DOI: 10.1249/MSS.0b013e31818ad117

11. O'Connell E.R., Thomas P.C., Cady L.D., Karwasky R.J. (1986). Energy costs of simulated stair climbing as a job-related task in fire fighting. Journal of Occupational Medicine 28(4), 282-284.

12. Hur P., Rosengren K., Horn G., Smith D., Hsiao-Wecksler E. (2013). Effect of protective clothing and fatigue on functional balance of firefighters. Journal of Ergonomics S2, 1-6. DOI: 10.4172/2165-7556.S2-004

13. Albert C.M., Mittleman M.A., Chae C.U., Lee I.M., Hennekens C.H., Manson JE. (2000). Triggering of sudden death from cardiac causes by vigorous exertion. The New England Journal of Medicine 343, 1355-1361. DOI: 10.1056/ NEJM200011093431902

14. Lee J.Y., Bakri I., Kim J.H., Son S.Y., Tochihara Y. (2013). The impact of firefighter personal protective equipment and treadmill protocol on maximal oxygen uptake. Journal of Occupational and Environmental Hygiene 10(7), 397-407. DOI: $10.1080 / 15459624.2013 .792681$

15. Peterson M.D., Dodd D.J., Alvar B.A., Rhea M.R., Favre M. (2008). Undulation training for development of hierarchical fitness and improved firefighter job performance. The Journal of Strength E Conditioning Research 22(5), 16831695. DOI: 10.1519/JSC.0b013e31818215f4

16. Lajoso-Silva N., Bezerra P., Silva B., Carral J.M.C. (2021). Functional training in portuguese firefighters: impact of functional training with or without personal protective equipment. Journal of Occupational and Environmental Medicine 63(4), el69-el76. DOI: 10.1097/JOM.0000000000002141

17. Stewart A., Marfell-Jones M., Olds T., De Ridder J. (2011). International Standards for Anthropometric Assessment. Lower Hutt, New Zealand: International Society for the Advancement of Kinanthropometry.

18. Heyward V.H., Gibson A. (2014). Advanced fitness assessment and exercise prescription. 7th ed. Champaign, IL: Human Kinetics.

19. Couto A., Carvalho I. (2012). PROCIV Technical Notebooks \#21, procedures guide for the constitution of permanent intervention teams. Portugal: Autoridade Nacional de Proteção Civil. (in Portuguese)
20. Karvonen M.J., Kentala E., Mustala O. (1957). The effects of training on heart rate; a longitudinal study. Annales Medicinae Experimentalis et Biologiae Fenniae 35, 307-315.

21. Pallant J. (2011). Spss Survival Manual: A step by step guide to data analysis using the SPSS Program. Australia: Allen \& Unwin.

22. Feairheller D.L. (2015). Blood pressure and heart rate responses in volunteer firefighters while wearing personal protective equipment. Blood Pressure Monitoring 20(4), 194-198. DOI: 10.1097/MBP.0000000000000120

23. Perroni F., Guidetti L., Cignitti L., Baldari C. (2015). Absolute vs. weight-related maximum oxygen uptake in firefighters: fitness evaluation with and without protective clothing and self-contained breathing apparatus among age group. PLoS One 10(3), e0119757. DOI: 10.1371/journal. pone.0119757

24. Rodríguez-Marroyo J.A., López-Satue J., Pernía R., Carballo B., García-López J. et al. (2012). Physiological work demands of Spanish wildland firefighters during wildfire suppression. International Archives of Occupational and Environmental Health 85(2), 221-228. DOI: 10.1007/s00420-011-0661-4

25. Smith D.L., Petruzzello S.J., Kramer J.M., Misner J.E. (1997). The effects of different thermal environments on the physiological and psychological responses of firefighters to a training drill. Ergonomics (1997) 40(4), 500-510. DOI: 10.1080/001401397188125

26. Poplin G.S., Roe D.J., Peate W., Harris R.B., Burgess J.L. (2014). The Association of Aerobic Fitness With Injuries in the Fire Service. American Journal of Epidemiology 179(2), 149-155. DOI: 10.1093/aje/kwt213

27. Elsner K.L., Kolkhorst F.W. (2008). Metabolic demands of simulated firefighting tasks. Ergonomics 51(9), 1418-1425. DOI: $10.1080 / 00140130802120259$

28. Calavalle A.R., Sisti D., Mennelli G., Andolina G., Del Sal M. et al. (2013). A simple method to analyze overall individual physical fitness in firefighters. The Journal of Strength $\mathcal{E}$ Conditioning Research 27(3), 769-775. DOI: 10.1519/ JSC.0b013e3182600554

29. Sheaff A.K., Bennett A., Hanson E.D., Kim Y.S., Hsu J. et al. (2010). Physiological determinants of the candidate physical ability test in firefighters. The Journal of Strength $\mathcal{E}$ Conditioning Research 24(11), 3112-3122. DOI: 10.1519/ JSC.0b013e3181f0a8d5

30. Prieto J.A., González V., Del Valle M., Nistal P. (2013). The influence of age on aerobic capacity and health indicators of three rescue groups. International Journal of Occupational Safety and Ergonomics 19(1), 19-27. DOI: 10.1080/10803548.2013.11076963

31. Mezzaroba P.V., Peserico C.S., Machado F.A. (2013). Effect of 27 weeks of mandatory physical training on physical fitness and anthropometry of newly hired firefighters. Brazilian Journal of Science and Technology 21, 103-11l. DOI: $10.18511 / 0103-1716 / \mathrm{rbcm} . v 2 \ln 4$ p103-111 (in Portuguese)

32. Lindberg A.S., Oksa J., Gavhed D., Malm C. (2013). Field tests for evaluating the aerobic work capacity of firefighters. PLoS One 8(7), e68047. DOI: 10.1371/journal. pone.0068047

33. Moore K.J., Penry J.T., Gunter K.B. (2014). Development of a walking aerobic capacity test for structural firefighters. The Journal of Strength $\mathcal{E}$ Conditioning Research 28(8), 23462352. DOI: 10.1519/JSC.0000000000000433

34. Rodríguez-Marroyo J.A., Villa J.G., López-Satue J., Pernía R., Carballo B. et al. (2011). Physical and thermal strain of firefighters according to the firefighting tactics used 
to suppress wildfires. Ergonomics 54(11), 1101-1108. DOI: 10.1080/00140139.2011.611895

35. Perroni F., Cignitti L., Cortis C., Capranica L. (2014). Physical fitness profile of professional Italian firefighters: differences among age groups. Applied Ergonomics 45(3), 456461. DOI: 10.1016/j.apergo.2013.06.005

36. Tierney M.T, Lenar D., Stanforth P.R., Craig J.N., Farrar R.P. (2010). Prediction of aerobic capacity in firefighters using submaximal treadmill and stairmill protocols. The Journal of Strength \& Conditioning Research 24(3), 757-764. DOI: 10.1519/JSC.0b013e3181c7c282

37. Smith D.L., Fehling P.C., Hultquist E.M., Lefferts W.K., Barr D.A. et al. (2012). Firefighter's personal protective equipment and the chronotropic index. Ergonomics 55(10), 1243-1251. DOI: 10.1080/00140139.2012.703696

Submitted: April 15, 2021

Accepted: June 15, 2021 